\title{
Sustentabilidade e lazer na pós-graduação latino-americana: conexões $^{1}$
}

\section{Sustainability and leisure in Latin American graduation: connections}

\author{
Mirleide Chaar Bahia, Christianne Luce Gomes, Rodrigo Elizalde, \\ Leonardo Lincoln Leite de Lacerda, Rodrigo Lage Pereira Silva
}

\begin{abstract}
RESUMO
Este artigo objetiva identificar e discutir conexões entre Sustentabilidade e Lazer/Ócio no contexto de cinco programas de mestrado e doutorado vinculados ao Conselho Latino-americano de Ciências Sociais/Rede CLACSO. Com enfoque qualitativo, a metodologia desta pesquisa foi baseada em estudo bibliográfico, aplicação de questionários e realização de entrevistas com estudantes, professores e profissionais vinculados aos programas dedicados às temáticas da sustentabilidade e meio ambiente que foram estudados, os quais são desenvolvidos nos seguintes países latino-americanos: Argentina, Brasil, Colômbia, Cuba e Equador. A análise dos resultados seguiu a estratégia de análise de conteúdo. Percebeu-se a necessidade de ampliar os entendimentos de sustentabilidade e de lazer, bem como de aprofundar conhecimentos sobre as conexões entre ambos. $O$ lazer aparece como uma possibilidade de prover experiências que instiguem a criticidade humana e, por consequência, a diminuição de práticas consumistas e degradadoras do ambiente, especialmente por meio do ecoturismo.
\end{abstract}

PALAVRAS-CHAVE: Sustentabilidade; Lazer/Ócio; Turismo; Ecoturismo; América Latina.

\section{ABSTRACT}

This paper aims to identify and discuss the connections between Sustainability and Leisure in the context of five master's and doctoral programs related to the Latin American Social Sciences Counsel/CLACSO Network. With a qualitative approach, the research methodology has been based on bibliographical study, questionnaire administration and interviews with students, professors and professionals related of the studied programs, which are dedicated to Sustainability and the Environment and are developed on the following Latin American countries: Argentina, Brazil, Colombia, Cuba and Ecuador. The analysis of the results followed the content analysis strategy. It was perceived the necessity to enhance the understanding on sustainability and leisure and on the connection between both. Leisure comes up as an alternative to provide experiences that instigate the human criticality and, therefore, could lead to the decrease of consumption practices and environment divisive practices, especially through ecotourism.

KEYWORDS: Sustainability; Leisure; Latin America. 


\section{Introdução: objetivos e metodologia da pesquisa}

O presente artigo é parte de uma pesquisa mais ampla e tem como objetivo identificar e discutir conexões entre Sustentabilidade e Lazer/Ócio no contexto de cursos de pós-graduação latino-americanos. Para delimitar o universo pesquisado, optou-se por investigar programas ligados à Rede CLACSO - Conselho Latino Americano de Ciências Sociais de Pósgraduação, selecionando os programas de mestrado e de doutorado dedicados às temáticas da sustentabilidade e meio ambiente. Nesse contexto, as discussões são aqui empreendidas buscando vincular essas temáticas com o lazer num sentido mais amplo e, conforme foi verificado no decorrer da pesquisa, ao final deste artigo são apontados alguns desafios para o turismo.

Com o intuito de obter informações para o estudo, a metodologia contemplou, na primeira etapa, uma pesquisa bibliográfica sobre as temáticas estudadas. Na segunda etapa, conforme previsto no protocolo aprovado pelo Comitê de Ética em Pesquisa da UFMG, foram selecionados os programas a serem pesquisados, definidos a partir da concessão de anuência institucional, sendo um total de 5 programas em 5 países diferentes (Argentina, Brasil, Colômbia, Cuba e Equador). Finalmente, na terceira etapa, foram aplicados 49 questionários (com professores, alunos e profissionais vinculados aos programas que concordaram com o Termo de Consentimento Livre e Esclarecido) e realizadas entrevistas com 11 voluntários, objetivando aprofundar as questões mais relevantes para a investigação.

As entrevistas foram realizadas on-line, por meio do programa Skype, que permite a comunicação com áudio e vídeo no computador. Além disso, o áudio das entrevistas foi gravado por meio do programa CallGrapher e, posteriormente, transcrito. $\mathrm{O}$ anonimato dos voluntários foi preservado e, neste artigo, os depoimentos obtidos foram destacados em itálico, indicando a fonte de obtenção das informações (questionário ou entrevista). O conjunto de informações coletadas passou pela análise de conteúdo, seguindo as diretrizes propostas por Laville \& Dionne (1999).

\section{Discussão preliminar: sustentabilidade ou desenvolvimento sustentável?}

Inicialmente, é importante salientar que os termos "sustentabilidade" e "desenvolvimento sustentável" sempre foram controvertidos e polêmicos, como foi destacado por um dos participantes da pesquisa: "Desarrollo sustentable: un término algo polémico que se usa, con varias lecturas del mismo, para describir los esfuerzos para combinar el desarrollo y el cuidado de la naturaleza." (Voluntário 40/ questionário).

Sustentabilidade e desenvolvimento sustentável, enquanto campo de estudos, práticas e intervenções, cada dia expressam mais a necessidade de desenvolver seu caráter multidisciplinar e interdisciplinar, apresentando distintas compreensões e abordagens desenvolvidas por diversas áreas do conhecimento. Por exemplo, foi afirmado o seguinte: "Los entendimientos de sustentable, sostenido, y sostenible tienen diversos enfoques de las ciencias 
naturales, la ingeniería, la sociología, la política y por supuesto la economía." (Voluntário 21/ questionário).

Apesar dos dois termos possuírem abordagens conceituais e enfoques diferentes, 24 dos 49 participantes da pesquisa emitiram entendimentos gerais, fornecendo respostas que incluíam ambos conceitos como se fossem sinônimos; ou expressando seu entendimento sobre apenas um dos termos, dando indícios de que os compreendem como iguais ou complementários, como é possível verificar em algumas das respostas:

[...] entendo os dois termos como sinônimos, se considerarmos que devem abranger aspectos de justiça social, e também que desenvolvimento não necessariamente está relacionado a crescimento econômico. (Voluntário 48/ questionário).

Son complementarios, el primero es perdurar en el tiempo, mientras que el segundo es la generación de competitividad ecológica, social y económica. (Voluntário 16/ questionário).

Acciones mejoramiento continuo y desempeño ambiental y social en las sociedades. (Voluntário 24/ questionário).

Logro de avances en el desarrollo humano involucrando los aspectos ambientales con los cuales se relaciona. (Voluntário 31/ questionário).

Literalmente se expresa en lograr que nuestro planeta tenga vida, que la relación hombre naturaleza tenga un equilibrio y se debe iniciar en los modos de vida de las personas hasta que empresarialmente los negocios no superen la degradación del ambiente. (Voluntário 34/ questionário).

De acordo com Banerjee (2006), "sustentabilidade" e "desenvolvimento sustentável" são terminologias que têm sido usadas, intercambiadamente, tanto nos discursos acadêmicos, quanto nos populares.

Considerando-se a origem etimológica do termo, sustentabilidade deriva do latim e significa sustentar ou manter algo firme. Seu conceito abrange diversos enfoques (pobreza, população, desmatamento, poluição, extinção de espécies, saúde, alimentação, trabalho, lazer, democracia e direitos humanos, entre outros) e "não deve se associar unicamente à 'natureza exterior'. [...] No século XXI, faz sentido considerar-nos nós mesmos como parte do discurso da sustentabilidade" (REDCLIFT, 2006, p. $51)$.

Os debates envolvendo o termo "sustentabilidade" vinculado a "desenvolvimento" emergiram mais fortemente a partir de 1980 e se preocupavam, de forma não exclusiva, mas com bastante particularidade, às necessidades humanas.

A disseminação de sistemas de medição para avaliar as variáveis ambientais, com uma ascendente busca por resultados e práticas que pudessem garantir a sustentabilidade (principalmente no âmbito de políticas 
e planejamentos estatais), "ampliou o uso de que foi objeto o termo 'sustentabilidade', e abriu um novo discurso sobre desenvolvimento, com um grande apelo aos tecnocratas e aos empresários" (REDCLIFT, 2006, p.52).

Outro aspecto a se analisar a partir dos resultados dos questionários é que, quando os dois termos são tratados como processos diferenciados, algumas compreensões demonstram estar embasadas naquilo que, em 1987, a Comissão Mundial sobre Meio Ambiente e Desenvolvimento descreveu como definição de "desenvolvimento sustentável", no relatório "Nosso Futuro Comum" ou "Relatório Brundtland". Esse documento postula que o "desenvolvimento sustentável é aquele que satisfaz as necessidades da geração presente sem comprometer a capacidade das gerações futuras para satisfazer suas próprias necessidades" (WCED, 1987, p.8).

As considerações efetuadas por diversos respondentes demonstram uma preocupação com a questão das gerações presentes e futuras, expressando a influência e difusão que o Relatório Brundtland tem, o que parece ser mais forte para pessoas vinculadas com os estudos da sustentabilidade e do desenvolvimento sustentável:

[...] desarrollo sustentable es la capacidad de poder suplir nuestras necesidades sin ir en detrimento de las necesidades del otro y del futuro. (Voluntário 09/ questionário).

Desde la ecología el mantenimiento de la diversidad y en cruce con lo socioeconómico la habilidad de las actuales generaciones por satisfacer sus necesidades sin comprometer los recursos de generaciones futuras. (Voluntário 15/ questionário).

Desarrollo sustentable: desarrollo de las comunidades y sus gentes que garantiza la utilización de los recursos y los cambios tecnológicos, de tal forma que permita satisfacer las necesidades actuales y de las generaciones futuras. (Voluntário 17/ questionário).

Explotación de los recursos naturales en función del crecimiento de la humanidad sin poner en riesgo a las generaciones futuras. (Voluntário 44/ questionário).

Conozco y asumo los contenidos que habitualmente se asignan al término, desde el Informe Brundtland en adelante. (Voluntário 38/ questionário).

Desarrollo sustentable, es el desarrollo social y económico de los individuos y las colectividades de tal manera que satisfagan las necesidades, pero pensando en las futuras generaciones, o sea que va de la mano con la sustentabilidad. (Voluntário 25/ questionário).

Sachs (2004, p.75) alerta que "não temos o direito de sacrificar a geração presente em prol de um futuro radiante para aqueles que virão depois de nós, da mesma forma que não temos o direito de privar as gerações futuras de herdarem um planeta habitável'. 
Cabe aqui ressaltar que 0 entendimento de desenvolvimento sustentável sistematizado no "Relatório Brundtland" vem recebendo algumas críticas daqueles que consideram a existência de diferenças significativas entre uma mesma geração referindo-se, principalmente às inter-classes sociais, as quais se refletem no acesso diferenciado à moradia, à educação, ao trabalho, à cultura, ao lazer, dentre outros.

Para Banerjee (2006, p. 78), por exemplo, esse conceito se baseia "num sistema único de conhecimentos e, a despeito de afirmar que aceita a pluralidade, há um perigo de marginalização ou de cooptação dos conhecimentos tradicionais à revelia das comunidades que dependem da terra para sua sobrevivência".

Sachs (2002) também chama atenção sobre o fato de que, independentemente da terminologia que se utilize (desenvolvimento sustentável ou ecodesenvolvimento), a abordagem fundamentada na harmonização de objetivos sociais, ambientais e econômicos não se alterou desde o encontro de Estocolmo até as conferências do Rio de Janeiro, realizadas em 1992 e, posteriormente, em 2012.

Mesmo com tais críticas, é possível vislumbrar caminhos possíveis, como Sachs (2002) defende, ressaltando que tal abordagem ainda é válida, desde que se atente para a recomendação da utilização dos oito critérios distintos de sustentabilidade (social, cultural, ecológico, ambiental, territorial, econômico, político nacional e internacional).

Outro aspecto positivo a se destacar é a percepção de que alguns dos participantes demonstram ter conhecimento desses critérios, emitindo sua compreensão sobre os termos e citando alguns destes, evidenciando ter noção da complexidade do assunto.

La sustentabilidad se enmarca en la comprensión de la dinámica humana en sus dimensiones biológicas, sociales, culturales, éticas, políticas, tecnológicas, entre otras; como un sistema complejo. Cuyo modelo de desarrollo por tanto requiere fundamentarse en aspectos como la integración de variables, la articulación de actores y sistemas, la viabilidad; Lo anterior desde una perspectiva humana y socialmente equitativa. (Voluntário 8/ questionário).

El desarrollo sustentable implica pasar de un desarrollo pensado en términos cuantitativos - basado en el crecimiento económico - a uno de tipo cualitativo, donde se establecen estrechas vinculaciones entre aspectos económicos, sociales y ambientales, en un renovado marco institucional democrático y participativo, capaz de aprovechar las oportunidades que supone avanzar simultáneamente en estos tres ámbitos, sin que el avance de uno signifique ir en desmedro de otro. (Voluntário 5/ questionário).

O interessante dessas repostas é a crítica, direta ou indireta, ao modelo de desenvolvimento baseado no crescimento econômico como 
forma de acesso ao desenvolvimento humano. Assim se fala da importância de passar dos critérios unicamente quantitativos a outros, também qualitativos. Nesta linha de raciocínio um participante explica que: "Desenvolvimento não necessariamente está relacionado a crescimento econômico" (Voluntário 10/ questionário).

Nessa direção,

[...] son ya muchos los economistas que han roto lanzas en contra del crecimiento económico visto como sinónimo de desarrollo. En la actualidad se multiplican los reclamos, sobre todo en los países industrializados, por una economía que propicie no sólo el crecimiento estacionario, sino el "decrecimiento" (ACOSTA, 2011, p.6-7).

Contrariamente, é muito comum a naturalização da ideia de que o alcance do desenvolvimento deve ser feito pela via do crescimento, como caminho principal e indispensável. Nesse sentido, é importante entender que muitas vezes isso é compreendido como forma única de assumir esse tema, como se pode observar nas respostas de alguns participantes:

El que conduzca al crecimiento económico, a la elevación de la calidad de la vida y al bienestar social, sin agotar la base de recursos naturales renovables en que se sustenta, ni deteriorar el medio ambiente 0 el derecho de las generaciones futuras a utilizarlo para la satisfacción de sus propias necesidades" (Ley 99 de 1993, artículo 3). (Voluntário 12/ questionário).

Es la capacidad de generar desarrollo económico, social, cultural, tecnológico, científico sin afectar de forma negativa el medio ambiente, pensando en las generaciones presentes y futuras. (Voluntário 20/ questionário).

Por "desarrollo sustentable" todo aquel que eleva la calidad de vida de las personas paralelamente al crecimiento económico de la región. (Voluntário 41/ questionário).

El desarrollo sustentable es el proceso de crecimiento socioeconómico y ético que protege el medio ambiente actual, sin poner en peligro la satisfacción de las futuras necesidades de generaciones venideras. (Voluntário 43/ questionário).

El combinar o conciliar los factores que permitan el desarrollo sostenible. El progreso económico, la inclusión y la equidad social y la preservación del medio ambiente para las actuales y fututas generaciones. Debe existir un equilibrio entre el progreso o desarrollo económico y la preservación del medio ambiente. (Voluntário 45/ questionário). 
Como se observa, a maioria das respostas sugere combinar crescimento econômico com proteção do meio ambiente, qualidade de vida das pessoas e com bem-estar social. Em contrapartida, foram poucos aqueles que mencionaram a problemática de manter os níveis de consumo atual, como enfatizado neste depoimento: "É um desafio para a humanidade que quer manter os padrões de consumo sem se responsabilizar pelas consequências socioambientais" (Voluntário 47/ questionário).

Pelo exposto, é imprescindível entender a ideia trabalhada por Herman Daly (1991), quando intitula seu artigo como: "Crecimiento sostenible: Un teorema de la imposibilidad". Qual é essa impossibilidade? Como o autor destaca, insustentável é o crescimento exponencial da economia em um mundo finito, como o Planeta Terra.

Adicionado a isso, Elizalde (2003, p.285) comenta que:

La historia del concepto de desarrollo sustentable muestra que es este un concepto equívoco y polisémico e incluso casi vacío. Hay desde quienes lo consideran un oxímoron, como Herman Daly (1991), si es que se lo entiende como crecimiento sustentable, hasta quienes lo han convertido en la versión actualizada del ya no tan nuevo mito desarrollista. Cada cual usa el concepto de sustentabilidad según mejor conviene a su particular interés y visión de mundo.

Nessa mesma linha, Elizalde assinala que, segundo Jorge Luis Borges, na figura que se chama oximoro (oxímorom), se aplica para uma palavra ou um epíteto que parece contradizer-se: assim os gnósticos falaram de uma luz escura; os alquimistas, de um sol negro.

Para mí el desarrollo sostenible es una contradicción. Cito a Nixon, que expresa esta idea más claramente: La expresión "desarrollo sostenible" es una contradicción en termino: un oxímoron. Es peligrosamente engañosa por cuanto nos ofrece la promesa de un desarrollo indefinido; nos dice que el desarrollo (el sustantivo) está por encima de la sostenibilidad (el adjetivo): que no existe una crisis que ponga en peligro la capacidad que tiene el planeta para sustentar la vida; y que el comportamiento de la especie humana para la ecosfera. O la relación entre los seres humanos y las demás especies de la tierra, no plantea conflicto alguno. (Voluntário 18/ questionário).

Ao homologar crescimento contínuo e ilimitado da economia com desenvolvimento sustentável, abre-se uma contradição insuperável. E paralelamente, como salienta Elizalde (2003), o conceito de desenvolvimento sustentável perde a possibilidade de realizar um questionamento radical ao estilo de desenvolvimento dominante, aos valores hegemônicos, à cosmovisão e paradigma vigente, e à civilização ocidental. 
Paralelamente acontece uma perda em seu conteúdo transformador e inicial impulso revolucionário, transformando-se em um discurso retórico.

Ademais, em muitos casos existe uma associação direta entre os conceitos crescimento sustentável e desenvolvimento sustentável, não havendo uma crítica ao entendimento e concepção de "desenvolvimento".

Outro tema pouco abordado no bojo dessas discussões é a naturalização da ideia da competição. Nessa lógica, na língua espanhola é muito comum confundir, e colocar como sinônimas, as palavras "competente" e "competição". Assim, muitas vezes quando se fala de competitividade, implicitamente se faz referência à ideia de ser mais competitivo, que não é o mesmo que ser mais competente. Desta forma o competir termina impondo seu entendimento, e assim se reforça a ideologia da competição como parte primeira da condição humana.

Comprende los procesos donde hay equidad, sostenibilidad y competitividad sustentados en principios éticos, socioeconómicos, culturales, ecológicos, políticos, institucionales, tecnológicos productivos, garantizando la justicia social y un crecimiento económico que respeta el entorno natural. (Voluntário 6/questionário).

Isso pode parecer algo irrelevante, mas expressa uma visão de mundo onde o "mais forte" tem que impor seu poder sobre o "mais débil". Assim se justificam as diversas formas de dominação, opressão e violência, marcando os modos supostamente normais de estabelecer relações entre os próprios seres humanos e destes com a natureza.

Outro aspecto a ser destacado é que, em geral, os olhares de muitos respondentes mostram, implicitamente, uma visão antropocêntrica, onde os seres humanos seriam os mais importantes no planeta terra.

\begin{abstract}
El desarrollo sustentable en primer lugar incluimos al hombre como pensador del desarrollo, y en segundo lugar son las estrategias, políticas y acciones encaminadas a suplir las necesidades del hombre y que propendan por mantener los recursos del medio ambiente y converjan en el término de sustentabilidad. (Voluntário 04/ questionário).
\end{abstract}

Com isso vemos que, em geral, as ideias sistematizadas por autores que criticam o modelo do desenvolvimento e crescimento ainda não são, necessariamente, incorporadas e muito consideradas. Contudo, é importante salientar que para um respondente a sustentabilidade e o desenvolvimento sustentável são compreendidos "desde los discursos desarrollados por Arturo Escobar" (Voluntário 36/ questionário).

Escobar (2011) é um autor que vem debatendo, entre outros temas, a necessidade de construir alternativas ao desenvolvimento, ou seja, de construir outro modelo que ele denomina de pós-desenvolvimento, para 
conseguir romper com a hegemonia da ideologia capitalista como o único modelo econômico e social possível.

Nessa perspectiva crítica, outro respondente indica que:

\begin{abstract}
Manejo una mirada crítica de estas nociones. Esto quiere decir que las entiendo y analizo como formas actuales hegemónicas de pensar el desarrollo y el manejo de recursos que, entre otras cosas, están orientando fuertemente las acciones en materia de gestión. (Voluntário 39/ questionário).
\end{abstract}

Expressa-se, assim, a necessidade de enfrentar a tensão existente entre as formas hegemônicas de entender o desenvolvimento e outras distintas, que apontam à necessária transformação do modelo extrativo e consumista vigente.

Junto com o que foi abordado anteriormente, existe outra tensão importante a se destacar: a busca da preservação e a percepção de um colapso eminente, o que exige avançar na construção de novos equilíbrios.

Sustentabilidade é um termo usado para designar ambientes ou sistemas biológicos/ecológicos/sociais que se mantém saudáveis, sem direcionarem-se para o colapso. (Voluntário 47/ questionário).

Entiendo la sustentabilidad como la capacidad de un organismo de permanecer y sobrevivir. (Voluntário 1/ questionário).

La sustentabilidad la percibo como un equilibrio entre el todo y sus partes. (Voluntário 41/ questionário).

Vários participantes da pesquisa salientaram a necessidade de buscar equilíbrios para avançar pela trilha da sustentabilidade. Para isso, é imprescindível respeitar os ritmos e ciclos da própria natureza e de seus ecossistemas, considerando que a intervenção humana sempre gera um impacto, sendo possível dizer que o cenário futuro é alarmante.

Cuando hablamos de sustentabilidad este hace referencia a la simbiosis entre actores que de alguna manera se necesitan y deben actuar para conservarse. (Voluntário 4/ questionário).

Va mucho más allá del concepto de sostenible, exige equilibrios reales entre dimensiones económicas, sociales y ambientales; exige que el sistema económico sea un subsistema de la biósfera. (Voluntário 11/ questionário).

La capacidad de utilizar los recursos naturales de manera adecuada, manteniendo en lo posible los equilibrios ecosistémicos no colocando el riesgo de la supervivencia de las futuras generaciones. (Voluntário 29/ questionário). 
Debe existir un equilibrio entre el progreso o desarrollo económico y la preservación del medio ambiente. (Voluntário 45/ questionário).

Pode-se dizer que nos programas de pós-graduação pesquisados, alguns dos respondentes do questionário apresentam uma visão crítica sobre sustentabilidade e desenvolvimento sustentável, dando indícios de que o programa onde estão vinculados discute e produz conhecimentos atualizados e aprofundados sobre tais temáticas.

Entretanto, como foi discutido neste texto, foi possível perceber que ainda existem fragilidades teóricas na abordagem, deixando alguns indicativos de que ainda se faz necessário um debate mais aprofundado sobre o tema da sustentabilidade ambiental a fim de que se compreenda, historicamente, como foi se constituindo esse debate.

Em síntese, destaca-se nas respostas dos participantes a forte influência do "Relatório Brundtland" no entendimento que eles têm de sustentabilidade e desenvolvimento sustentável. Sobressai também a forte vinculação que se estabelece entre desenvolvimento humano e crescimento econômico. Nessa mesma linha, outro elemento ressaltado é o pouco aprofundamento quanto às ideias do "Relatório Brundtland" e ao modelo capitalista extrativo e consumista que, segundo nossa perspectiva, é o grande gerador da situação de crescente insustentabilidade global do presente.

Além disso, as respostas de alguns voluntários evidenciaram que, por vezes, o termo "sustentabilidade" parece indicar um universo menor, como um organismo ou um determinado território. Uma ideia mais biológica que é reforçada com certas palavras como "sobrevivência do organismo", "simbiose", "sustentar a si mesmo", território que gerencia seus recursos. Já o entendimento de "desenvolvimento sustentável" parece indicar algo supostamente maior, mais complexo, abrangendo uma comunidade ou sociedade e suas facetas (política, econômica, etc.). Essa constatação revela a necessidade de buscar um equilíbrio entre os diversos interesses do ser humano com a natureza, ou uma forma de crescer sem comprometer a gerações futuras.

É importante salientar que, segundo Attali (1982), a crise é uma larga e difícil reescrita que separa duas formas provisionais do mundo, aquela que é necessária abandonar por mostrar-se incapaz de resolver os problemas do presente e uma visão alternativa e inovadora que pode permitir a evolução e a transformação das sociedades humanas.

Por isso, pode ser que o mais importante e essencial de recuperar sejam os sonhos e a esperança no futuro, como enfatizaram dois voluntários da pesquisa:

Entendo como uma utopia, no sentido de que são úteis como uma meta a ser alcançada. (Voluntário 48/ questionário).

Sustentabilidade é [...] uma utopia que na minha opinião nunca conseguirá ser alcançada, mas mesmo assim sempre deve ser buscada. (Voluntário 47/ questionário). 
Como pondera Galeano (1994), baseado em Fernando Birri, "a utopia está no horizonte. Podemos nos aproximar dois passos, enquanto ela se afasta dois passos. Caminhamos dez passos e o horizonte corre dez passos. Por mais que caminhemos, jamais alcançaremos. Então, de que serve a utopia? Serve para isso: para que as pessoas não deixem de caminhar".

Para continuar caminhando é preciso vislumbrar possibilidades que nos direcionem e incentivem na caminhada. Por isso, para além das discussões teóricas, essa pesquisa buscou saber, por meio de entrevistas a alguns dos participantes voluntários, quais as experiências vividas por estes de forma pessoal, profissional, educacional e em voluntariado e quais as articulações possíveis entre sustentabilidade e lazer, conforme será tratado a seguir.

\title{
Experiências vinculadoras entre lazer e sustentabilidade
}

Alguns voluntários da pesquisa, quando questionados sobre 0 conhecimento de experiências práticas que vinculassem as temáticas lazer e sustentabilidade, relacionaram-nas de forma mais geral, indicando que o modo de viver e as ações das pessoas no mundo, sejam elas nos momentos de tempo livre (numa viagem, por exemplo) ou nos momentos de trabalho, deveriam estar, via de regra, embasadas numa constante preocupação com a forma de consumo da sociedade, com o seu bem estar e com a sustentabilidade do planeta.

\begin{abstract}
Pues haber, yo pienso que todas las acciones que realizamos las personas, sea en el trabajo, en el hogar o en nuestro tiempo libre, todo tiene un impacto en el mundo que hemos creado y en el mundo natural como tal. Yo pienso que las acciones, la forma en que las llevamos a cabo, la forma en que consumimos, los hábitos de consumo, los hábitos que tenemos en nuestra casa, digamos cuando hacemos un viaje de turismo, como el que hice yo o un viaje por trabajo, todo eso tiene un impacto. Entonces ahí con el tema de la sustentabilidad tiene una relación estrecha. Pienso que todo impacta de alguna manera en los ecosistemas, en la sociedad, en nosotros mismos, en todo. Entonces es como ver esa relación. (Voluntário 1/ entrevista).
\end{abstract}

Para o voluntário 9, as possibilidades de se vivenciar os momentos de lazer relacionam-se com outros valores e atitudes para além do consumismo. No seu entender, é preciso aprender a desfrutar das coisas simples da vida com a família e com os amigos e que isso depende de um componente fundamental: a educação. Esta que possibilita a consciência sobre o uso racional e o consumo racional dos recursos naturais.

Se puede relacionar fundamentalmente en un componente que es la educación, pero entendiendo el uso racional y el consumo racional de las cosas. Es decir, cuando nosotros 
hablamos del concepto de sustentabilidad, pero a la vez de ocio, tenemos que estar muy conscientes de cuál es el impacto que podemos tener a través del mismo. Podemos mirarlo el ocio como un componente minimalista, es decir la simplicidad, o sea aprender a disfrutar de las cosas simples de la vida, de un atardecer, de caminar con la familia, o de compartir con los amigos un diálogo, sin ir en detrimento de los recursos. (Voluntário 9/ entrevista).

Subjetivamente, essa fala vem ao encontro do que Guattari (1990) registra em suas reflexões e preocupações sobre as intensas transformações no planeta e os resultados que estas vêm causando nos indivíduos e na sociedade, inclusive citando que as relações subjetivas estabelecidas entre familiares, entre amigos, entre vizinhos e entre ser humano-natureza são de extrema importância; entretanto, têm-se deteriorado muito nos últimos tempos, como reflexo de alguns valores e atitudes vividos na atualidade.

É possível perceber que há uma interligação entre problemas vivenciados no seio das relações familiares, das relações de trabalho, das relações entre gêneros e das relações com o meio ambiente, e que estes problemas dizem respeito à subjetividade humana.

[...] é nesse contexto de ruptura, de descentramento, de multiplicação dos antagonismos e de processos de singularização, que surgem as novas problemáticas ecológicas [...] parece-me que elas evocam uma problematização que se torna transversal a essas outras linhas de fratura (GUATTARI, 1990, p. 14)

A problemática ambiental, mais que uma crise ambiental, seria um questionamento do pensamento e do entendimento sobre as atitudes vividas na atualidade e as relações estabelecidas na sociedade capitalista, no que se refere à busca de um desenvolvimento pautado na lógica do consumo, da dominação da natureza e dos recursos naturais (BAHIA, 2005). pesquisa:

Esse tipo de atitude foi claramente apontado por voluntários da

Ahí hay un componente fuerte porque la humanidad está ligando el ocio con el consumo. Inclusive la alegría y la felicidad con el consumo. Incluso ahí viene un componente de conflicto que se está generando fuertemente y se está generando una corriente, como un minimalismo extremo, es decir poder disfrutar de las cosas sin necesidad de consumir, sin necesidad de destruir. O que si el consumo es mínimo, incluso que sea renovable y sustentable. (Voluntário 9/ entrevista).

Conservação e desenvolvimento integrado, significa que a gente está pensando no desenvolvimento integrado a conservação ambiental. E ai especificamente, a gente está trabalhando numa comunidade que está localizada na zona 
de amortecimento de um parque estadual. $E$ onde as pessoas enxergam o potencial para o turismo, um potencial para o lazer de pessoas que, muitas vezes, vem de cidades maiores de São Paulo, Campinas e outros cantos. Mas elas, e a gente também, têm noção que não é "Ah vamos atrair o turismo e desenvolver economia!". Se não pesar isso integrado com a dimensão ambiental, da sustentabilidade ambiental e também da cultura, da preservação da cultura. Acho que corre-se um risco muito grande. (Voluntário 48/ entrevista).

Um dos entrevistados considera importante articular as temáticas lazer e sustentabilidade e ressalta sua preocupação com as gerações futuras. Na sua percepção, há experiências positivas por meio do turismo sustentável:

Bueno, básicamente, sustentabilidad, ocio y recreación deberían ir unidas, deberán ser un solo contexto. ¿Por qué razón? Porque en la medida en que el ocio y la recreación sean sustentables, en el largo plazo esos espacios se van a poder respetar y se van a poder adecuar para las futuras generaciones. Entonces desde el punto de vista personal, efectivamente hay algunas experiencias que se han manejado en cuanto hacia la sustentabilidad en ese contexto. Por ejemplo, aquí cerca de nuestra ciudad tenemos un parque nacional, el Parque de Chicamocha, donde el contexto de la sustentabilidad está muy arraigado. Se promueve mucho el turismo sostenible, el turismo que respete la naturaleza, respete los ecosistemas. El turismo de miren pero traten lo menos posible de impactar en esos ecosistemas. (Voluntário 22/ entrevista).

O Turismo Ecológico/Ecoturismo geralmente é lembrado quando se articula as temáticas lazer e sustentabilidade, pois, por vezes, tal prática contempla um misto de conscientização ecológica, aprendizagem informal e prazer. Alguns exemplos desse tipo de experiência são a caminhada na mata, a observação de animais, o estudo científico, o ato de fotografar, o mergulho, entre outros.

Entretanto, alguns entrevistados refletiram sobre como o próprio turismo ecológico ou ecoturismo, se desenvolvido ou vivenciado de forma irresponsável, pode gerar muitos impactos socioambientais, indo contra os próprios princípios da sustentabilidade.

[...] espera-se do ecoturista um comportamento diferenciado daquele do turista convencional. O primeiro deve possuir uma ética ambiental e boa vontade de não degradar 0 recurso visitado; deve ter foco na motivação intrínseca e não extrínseca; ter orientação biocêntrica em vez de antropocêntrica e a intenção de beneficiar a vida selvagem e o ambiente natural; além de procurar uma experiência direta com tal ambiente. Quanto ao quesito educacional, espera-se 
que o ecoturista procure e tenha expectativa de educação e apreciação; além de alta dimensão cognitiva e afetiva. Comparando os turistas convencionais aos ecoturistas, os primeiros em férias têm a tendência de apresentar atitudes menos conscientes para como o ambiente, ao passo que os ecoturistas tentam minimizar os impactos de sua visita no local de destino (HINTZE, 2009, p. 71).

Cabe aqui salientar sobre o "amor por temporada" que Burne e Dachary (2004) informam quando se trata de estreitar relações entre turismo e sustentabilidade. Isso porque o Turismo e suas outras modalidades, como - Ecoturismo, é, em menor ou maior grau, uma área de expansão da globalização, evocando discursos ingênuos e utópicos para muitas realidades, já que frequentemente gera pouco avanço social, ecológico, econômico e cultural.

Por isso, fala-se tanto da importância da educação como um componente essencial para se vincular lazer e sustentabilidade de forma responsável:

Entonces la gente piensa, por ejemplo, que un turismo ecológico es venir y recorrer un sendero. Pero en esos recorridos del sendero las personas cometen el error ir contaminando, de no hacer recuperación o reciclaje, o van destruyendo parte de la biota o la biomasa, y ellos creen saber de ecología cuando en realidad están violentando la ecología. Inclusive ahora se está buscando la manera de mitigar eso. (Voluntário 9/ entrevista).

Lo primero es la educación. Concienticen a quién va a hacer uso del servicio, para que ahí si pueda empezar a integrarse a un proceso sustentable, que no solo sea económicamente rentable para el hotel, sino que también sea amigable con el medioambiente y a su vez respetuoso con el entorno. $Y$ aquí hay un componente adicional y la cultura. El componente cultural, nuestra historia, nuestras tradiciones. Nosotros compartimos eso y al ocio lo tenemos que ligar con ese componente cultural y social, donde las comidas, los bailes, la literatura nuestra la compartamos. $Y$ eso es parte de nuestra sustentabilidad. Entonces si existen contribuciones, pero tenemos que pensar en ligar el componente cultural, ya que no es algo estrictamente ambiental. (Voluntário 9/ entrevista).

[...] se a gente for considerar lazer como, muitas pessoas dizem aqui em São Paulo, que é ir à praia, que é grande divertimento, se eu for pensar pela experiência de turistas que eu vejo na praia aí eu não vejo nada de sustentável. Não é sustentável você ver um local que tem a capacidade " $X$ " de comportar uma população, de receber lixo, esgoto. Uma população litorânea, um local litorâneo que tem uma capacidade de prover uma população com qualidade ambiental, com qualidade de praia, qualidade das águas que 
está ligada a qualidade da praia, e aí recebe um fluxo de turistas que às vezes multiplica em duas, três vezes a população. (Voluntário 47/ entrevista).

Hintze (2009, p. 74) considera de extrema importância a possibilidade do ato educativo, por meio dessa aproximação ser humano-natureza, tomando como base a possibilidade de ações de Educação Ambiental nãoformal por meio de vivências de Ecoturismo "[...] pois durante as visitas a ambientes naturais, o condutor de grupos assume o papel de educador, conduzindo os ecoturistas e tendo a oportunidade de promover situações que se convertam em experiências educativas".

Como defende Serrano (2000), o lazer na natureza deve servir para uma reflexão, e não para uma alienação e fuga da realidade:

Procurar a natureza para lazer, descanso e relaxamento, seja através da contemplação, seja através da "adrenalina", não deve servir para que esqueçamos o humano que marca nosso cotidiano, mas para que reflitamos sobre ele. (SERRANO, 2000, p. 17).

Vale lembrar que o Turismo Ecológico ou Ecoturismo surgiu como uma alternativa de se contrapor à lógica do turismo de massa (estandardizado e predatório), e procura cada vez mais defender a proposição de roteiros personalizados, preocupados com o mínimo impacto e com grande interesse paisagístico-ecológico (SERRANO, 1997). Entretanto, há preocupações quanto à prática equivocada deste segmento:

[...] o ecoturismo vem perdendo sua capacidade de crítica às formas tradicionais de organização das viagens para as massas, pois passou igualmente a empacotar com 'embalagens recicláveis', é certo, natureza e subjetividade, disponibilizando-as para um consumo rápido e fácil (SERRANO, 2000, p. 16).

$\mathrm{Na}$ "indústria turística", o segmento do ecoturismo é o que apresenta maiores taxas de crescimento. Se ainda levarmos em consideração o crescimento de outros sinais da busca da natureza também associados ao mesmo universo mental das práticas do ecoturismo, como as medicinas alternativas, a alimentação natural e os esportes praticados em ambientes naturais, sem tocar na disseminação do ambientalismo - sem dúvida a maior influência ao crescimento desse tipo de interesse, é impossível negar sua importância como fenômeno social. Da mesma forma, não é possível negligenciar os impactos sociais e naturais decorrentes de seu desenvolvimento, em que pese a retórica do "baixo impacto", centrada na imagem do turismo como "indústria limpa", característica de seu marketing (SERRANO, 1997, p. 16-17) 
Ao sistematizar alguns dos principais processos de impactos do lazer na natureza, Barros e Dines (2000, p.58), os agrupam em dois aspectos: "ecológicos, quando provocam alterações no ambiente, degradando o solo, a vegetação, os recursos hídricos e a fauna, e sociais, quando causam uma diminuição na qualidade da experiência dos visitantes".

Em um passeio por áreas naturais é comum encontrar sinais evidentes de impacto no ambiente como erosão em trilhas, restos de fogueira por toda parte, lixo, locais devastados por "trilheiros", etc. [...] Há outros impactos graves que não são tão aparentes, como a contaminação das águas, a mudança de hábito da fauna, a alteração na dinâmica de ecossistemas, a ausência de certas plantas nativas, o decréscimo na natalidade de espécies ameaçadas, etc. (BARROS; DINES, 2000, p. 71).

Em âmbito mais geral, Guattari (1990) não apenas denuncia a problemática atual, demonstrando pontos de fragilidade existentes na sociedade e nas relações estabelecidas por esta, como também anuncia caminhos para a recomposição das relações humanas em seus diversos âmbitos, propondo a lógica de um novo paradigma filosófico, que este denomina como "ecosófico".

[...] é concebível em compensação que a nova referência ecosófica indique linhas de recomposição das práxis humanas nos mais variados domínios. Em todas as escalas individuais e coletivas, naquilo que concerne tanto à vida cotidiana quanto à reinvenção da democracia - no registro do urbanismo, da criação artística, do esporte etc - trata-se, a cada vez, de se debruçar sobre o que poderiam ser os dispositivos de produção de subjetividade, indo no sentido de uma re-singularização individual e/ou coletiva, ao invés de ir no sentido de uma usinagem pela mídia, sinônimo de desolação e desespero (GUATTARI, 1990, p. 15).

Essa re-singularização individual e/ou coletiva apontada por Guattari (1990), pode seguir caminhos alicerçados nas possibilidades educativas, tanto de forma sistemática (ensino formal) e/ou assistemática (ensino não formal). Portanto, seja na escola, na universidade, na cidade, no parque, nas vivências cotidianas (de lazer ou não), a educação (ambiental ou geral) é apontada como uma das principais vias para se vislumbrar uma sociedade mais sustentável.

Isso é demonstrado nas falas dos participantes da pesquisa, que se mostram engajados em alguma ação que envolva a educação sistemática ou assistemática. E o tempo de lazer aparece como um importante e significativo tempo de possibilidades educativas dos indivíduos e da sociedade. 
Respecto a las actividades en el tiempo de ocio podría yo referir que he realizado y que están relacionadas con la sustentabilidad, realmente estás estarían enfocadas más en el tema de educación ambiental que es un pilar que para mí es importante a nivel social. Nosotros hemos venido trabajando no solamente con la comunidad académica de las universidades a las que pertenezco, sino que adicionalmente en nuestra comunidad en la que habitamos aquí en el condominio al que yo pertenezco, en el barrio donde yo me ubico. Nosotros en comunidad hemos desarrollado algunas estrategias que nos permiten reducir... a la vez que reducimos unos costos relacionados con el tema de la recolección de los residuos en el condominio y que básicamente están centrados en que todos llevamos a un mismo lugar los residuos, para con ello reducir los costos de recolección. Esto ha sido un ejercicio educativo que hemos hecho en tiempo diferente del tiempo laboral y ha contribuido, de alguna manera, a garantizar mejores prácticas ambientales con la comunidad con la que nosotros estamos aquí habitando. (Voluntário 13/ entrevista)

Da minha experiência profissional eu claramente vejo vínculos, sou bióloga e fiz trabalhos com educação ambiental em jardim botânico de Porto Alegre, a partir dessa experiência eu vejo vínculo entre a educação ambiental com a sustentabilidade, porque esse jardim botânico tinha uma sessão de educação ambiental que tinha várias atividades para escolares e idosos, e proporcionavam atividades que eu considero lazer que o pessoal ia para lá para divertir, passar bons momentos e juntava com um pouquinho de popularização da ciência e atividades de educação voltadas para o conhecimento de natureza e atividades voltadas para tratar questão ambiental e a sustentabilidade entrava nisso. (Voluntário 47/ entrevista).

Eu trabalho em uma comunidade em São Judas do Paraitinga, que tem um potencial muito grande para 0 turismo de base comunitária. Apesar da gente saber isso na teoria ou racionalmente, a gente percebeu isso na prática que não dá para dissociar a questão da conservação ambiental com a cultura, a valorização cultural, 0 desenvolvimento social e o desenvolvimento econômico. As coisas têm que estar todas articuladas. E eu pessoalmente acredito muito em processos que partem de dentro para fora. Entrando no campo do turismo, não é um turismo a qualquer preço. Enfim aí eu já acho que estou muito pelo campo da minha experiência, do trabalho que eu estou fazendo atualmente [...]. (Voluntário 48/ entrevista)

É preciso considerar o duplo aspecto educativo do lazer, de forma a compreendê-lo como objeto e veículo de educação. A vivência do lazer pode ampliar possibilidades de aprender a usufruí-lo com mais criticidade, criatividade e autonomia. A condição primeira e primordial é a adoção de 
medidas que possibilitem a participação popular, para um conhecimento, entendimento e valorização do lazer (BAHIA, 2005).

O reconhecimento deste duplo aspecto educativo está baseado em duas constatações:

[...] a primeira, que o lazer é um veículo privilegiado da educação; a segunda, que para a prática das atividades de lazer é necessário o aprendizado, o estímulo, a iniciação aos conteúdos culturais, que possibilitem a passagem de níveis menos elaborados, simples, para níveis mais elaborados, complexos, procurando superar o conformismo, pela criticidade e pela criatividade (MARCELLINO, 1996, p. 50).

Outro aspecto de extrema importância é a compreensão de que o lazer pode ser um instrumento de mudança social, tendo em vista superar a visão funcionalista e trazer valores revolucionários, capazes de educar as pessoas para vivenciarem de forma crítica e criativa os seus momentos de lazer e de trabalho. Como diz Marcellino (1996, p.26), "são reivindicadas formas de relacionamento social mais espontâneas, a afirmação da individualidade, a convivência com, ao invés do domínio sobre a Natureza”.

Os impactos socioambientais causados pela visitação e prática de lazer em áreas naturais deve ser gerenciado de modo a não afetar a conservação e os modos de vida das populações tradicionais residentes em tais áreas. Para isso, tanto a educação pelo e para o lazer, a educação ambiental e o planejamento da visitação tornam-se atividades fundamentais e devem utilizar-se de formação profissional daqueles que irão atuar como promotores das atividades, além de ferramental e métodos que conciliem uso e conservação.

O turismo nos espaços naturais, levando em consideração a questão praxiológica, demonstra ser uma saída possível para o uso de áreas naturais protegidas pela atividade turística, objetivando a sua preservação. Pois, a atividade, quando vista e planejada como um evento, fato, ou conjunto de relações que envolve infinitas facetas do existir humano, valoriza o atrativo natural e sai da superficialidade comercial para um espaço qualitativo de reflexão, de reencontro entre o homem e o meio ambiente (PINHEIRO; SOARES; AZEVEDO, 2010, p. 337).

O uso público em áreas ambientais preservadas e regulamentadas pode trazer impactos que podem ser minimizados se forem considerados dois aspectos complementares entre si: "1. a ampla divulgação em campanhas permanentes de informação sobre a ética e as práticas de mínimo impacto; 2. a adoção de instrumentos e ações de manejo que 
contribuam para a minimização dos impactos" (BARROS; DINES, 2000, p. 50)

As ações com potencial para minimizar impactos podem envolver práticas de lazer e de turismo. Contudo, apesar das possíveis contribuições, também existem incongruências entre Turismo, Lazer e Sustentabilidade. Assim, Turismo e Lazer podem colaborar para a busca de um equilíbrio entre a utilização de recursos atuais e futuros, como defendido pelo "Relatório Brundtland" - ao propiciarem mudanças de hábitos e comportamentos de maneira mais prazerosa, harmoniosa, paulatinamente e de forma constante, por exemplo. Ademais, podem reforçar o consumismo e a depredação de espaços. Ambas situações podem ser investigadas no contexto do turismo ecológico e da educação ambiental, que, muitas vezes contemplam uma vertente educativa que vislumbra nas práticas de lazer, um valioso veículo de aprendizagem.

Dessa forma, cabe ressaltar a ética e as práticas de mínimo impacto em quaisquer atividades realizadas em áreas naturais, sejam unidades de conservação ou não. Conforme lembram Barros e Dines (2000), as práticas de manejo da visitação poderão ser aplicadas principalmente em áreas consideradas como unidades de conservação, embora possam ser utilizadas em outras áreas naturais onde se pretenda compatibilizar o uso público ligado ao lazer com a conservação do ambiente e dos ecossistemas naturais existentes em tais espaços.

\section{Considerações finais}

No que tange às compreensões acerca de meio ambiente, foi identificada uma associação difusa envolvendo os termos crescimento, desenvolvimento, desenvolvimento sustentável e sustentabilidade. Tendo como base o aumento, quase que exclusivamente do setor econômico, o crescimento atrela os preceitos do modelo capitalista que vigora em grande parte do planeta, criando a sensação de que é possível um crescimento exponencial mesmo em um mundo finito. Esse aspecto foi criticado pelos voluntários, que preferem tratar do termo sustentabilidade agregando a ideia de que o crescimento precisa ser repensado para que os recursos existentes não fiquem escassos e/ou não prejudiquem as gerações presentes, nem as futuras, em vista de um mundo mais promissor.

Ao abordar o tema dessa forma, foi possível constatar que muitos voluntários assimilaram ideias contidas no "Relatório Brundtland", apesar de haver ressalvas por certos conteúdos desatualizados nesse documento. A partir desse entendimento, a palavra "desenvolvimento" começou a ganhar espaço nas discussões sobre o assunto, trazendo outros pilares como 0 aspecto ecológico e o social, sem, contudo, abandonar o forte preceito econômico como grande indutor de bem-estar social.

Apesar de que inúmeras nomenclaturas e classificações podem muitas vezes trazer outros caminhos e empecilhos à causa, fica evidente que tais ações acabam gerando reflexões e planejamentos para que ações mais eficazes e condizentes com as exigências do novo mundo se perpetuem. 
Nesse sentido, algumas generalizações acabam servindo de base ao desenvolvimento sustentável, sem, no entanto, desconsiderar o contexto específico de aplicação das ideias e planos. Por isso a consideração de que trabalhar em prol desse tipo de desenvolvimento exige cada vez mais a polivalência, tanto de profissionais multi e interdisciplinares, quanto de voluntários, residentes e órgãos públicos. Generalizações que não escapam de diversidades, controvérsias e polêmicas, como se sucedeu ao se perguntar aos pesquisados 0 entendimento sobre sustentabilidade $e$ desenvolvimento sustentável. Em muitos casos, ambos os termos foram assimilados como sinônimos ou similares.

O próprio termo desenvolvimento sustentável carrega em si uma contradição: a de passar uma ideia simultânea de abrangência (abordando política, economia, sociedade, etc.) e um conceito mais específico (sobre organismo, território e um pensamento biológico). Além disso, existe sempre o peso de colocar o ser humano como centro das considerações, marcando uma postura antropocêntrica.

Nesse tipo de entendimento, quando em momentos de crise, o ser humano sempre acaba recebendo maior atenção do que a natureza, reforçando um tipo de visão que perpetua a crença de um desenvolvimento danoso, pautado no crescimento unilateral, no consumismo, na concentração de riquezas e distribuição de pobrezas. E esse tipo de crítica ao modelo adotado atualmente foi encontrado na pesquisa realizada, mas de forma pontual e pouco aprofundada.

Percebeu-se, nos relatos dos voluntários, a necessidade de ampliar o comprometimento com o presente e o futuro do mundo, direcionada e baseada em valores como o respeito, o equilíbrio, uma filosofia mais conjuntiva que concentradora de condições e vantagens e a equanimidade das relações entre flora e fauna (incluindo aí o ser humano).

Nesse sentido, mostra-se a relevância de considerar o tempo de planejamento e de ações tendo como referência também o tempo da natureza, uma vez que o curto, médio e longo prazos humanos são bem diferentes daqueles medido pelo restante do meio ambiente: em alguns casos menores (como de animais diversos) e em outros casos maiores (como algumas plantas, ecossistemas e matérias orgânicas e inorgânicas).

A temática da sustentabilidade refere-se ao desafio do desenvolvimento, que precisa ser assumido como responsabilidade não somente de centros de formação, de pesquisa e extensão, concentrados muitas vezes nos grandes centros urbanizados, uma vez que possui caráter transversal em todos os territórios e espaços considerados. Claro que relevando as características peculiares a cada espaço e o poder de decisão de cada ser humano.

Também, há que lembrar a possível contribuição que a esfera do lazer pode fornecer para a sustentabilidade quando instiga a diminuição do consumismo e propicia o repensar quanto à importância de bens materiais. Com isso, torna-se fundamental priorizar vivências de lazer que enfatizem o relacionamento entre os seres vivos, como sugere o turismo ecológico ou ecoturismo. Essas propostas pretendem ser alternativas ao desenvolvimento 
vigente, mas, quando são reduzidas a modismos, acabam perdendo sua capacidade crítica.

Nesse sentido, a educação ambiental se mostrou uma área próxima e fácil de assimilar junto ao lazer, que podem trabalhar juntos em prol do ideal de sustentabilidade por possuir características como 0 prazer, a dinamicidade e espaço natural. Além disso, inúmeras outras afinidades foram identificadas entre lazer, sustentabilidade e meio ambiente, dentre as quais pode ser citado o turismo como um importante tema de fronteira. $O$ assunto foi amplamente enfatizado pelos voluntários. Talvez porque turismo e lazer, bem como turismo e sustentabilidade têm relações estreitas, fáceis de serem identificadas na vida cotidiana das pessoas, apesar de serem áreas complexas de serem delineadas.

Entretanto, o turismo e suas ramificações (ecoturismo/turismo ecológico, agroturismo, turismo de aventura, entre outras) apresentam contradições de sentidos e ações, em grande parte, por causa do sistema econômico a que estamos expostos, induzindo mais problemas que soluções. Isso acaba por contribuir com a ideia de que teoria e prática não se mesclam.

Portanto, é necessário pensar no desenvolvimento do turismo voltado à efetiva busca da sustentabilidade, promovendo o envolvimento da população local no planejamento participativo dos projetos a serem implantados na região em questão, o desenvolvimento econômico da região, o respeito aos ecossistemas locais e o respeito às formas de manifestação cultural da população local. Além disso, é preciso que o Poder Público se comprometa em desenvolver estratégias para a implementação de políticas de turismo e elaboração de planos de manejo de áreas naturais protegidas, dialogando e envolvendo o setor privado e a população residente nas áreas onde estas deverão ser implementadas (BAHIA, 2005).

Em síntese, por ser a vinculação do lazer com a sustentabilidade e o meio ambiente algo pouco estudado, contém um grande potencial para desvelar novas formas de avançar nos desafios expostos, o que é especialmente relevante frente uma realidade social e ambiental que mostra claros sinais de crescente insustentabilidade global. É notória e urgente a necessidade de construir novas compreensões a partir das quais se possa problematizar as práticas de lazer e de turismo em sua vinculação com a sustentabilidade ambiental e social. Espera-se que este estudo possa estimular novos estudos e pesquisas sobre essa temática, assim como a elaboração de propostas e ações estratégicas nos campos do lazer e do turismo, que sejam comprometidas com os desafios da sustentabilidade do presente e do futuro que se almeja construir.

\section{Referências bibliográficas}

ACOSTA, Alberto. La Naturaleza con Derechos: Una propuesta de cambio civilizatório. $2011 . \quad$ Disponível em hhttp://www.lai.at/attachments/article/89/AcostaNaturaleza\%20Derechos\%202011.pdf 
ATTALI, J. Los tres mundos (para una teoría de la post-crisis).Madrid: Cátedra, 1982.

BAHIA, M.C. Lazer - Meio Ambiente: em busca das atitudes vivenciadas nos Esportes de Aventura. 2005. Dissertação (Mestrado em Educação Física) Universidade Metodista de Piracicaba - UNIMEP, Piracicaba, SP, 2005.

BANERJEE, S.B. Quem sustenta o desenvolvimento de quem? O desenvolvimento sustentável e a reinvenção da natureza. In: FERNANDES, M.; GUERRA, L. (Orgs.). Contra-discurso do desenvolvimento sustentável. 2 ed. Belém, Associação de Universidades Amazônicas, 2006, p. 77-128.

BARROS, M.I.A.; DINES, M. Mínimo impacto em áreas naturais: uma mudança de atitude. In: SERRANO, Célia (org). A educação pelas pedras: ecoturismo e educação ambiental. São Paulo: Chronos, 2000, p. 47-84.

BURNE, S.M.A.; DACHARY, A.C. Sustentabilidad, pobreza y turismo. Estudios y Perspectivas en Turismo, v. 13, 2004, p.160-173.

DALY, H.E. Crecimiento sostenible: Un teorema de la imposibilidad". Madrid: Desarrollo, № 20, 1991, p. 47-49.

ESCOBAR, A. Más allá del desarrollo: postdesarrollo y transiciones hacia el pluriverso. Revista de Antropología Social, Universidad Complutense de Madrid, Vol. 21, 2012, p.23-62. Madrid: Universidad Complutense de Madrid, 2012.

Disponível

em: http://revistas.ucm.es/index.php/RASO/article/viewFile/40049/38479

ELIZALDE, A. Desde el desarrollo sustentable hacia sociedades sustentables. Revista Polis, vol. 1, núm. 4, Santiago: Revista de la Universidad Bolivariana, 2003, p.285-319. Disponível em:

http://www.redalyc.org/pdf/305/30500411.pdf

ELIZALDE, R. EI Ocio entendido desde la teoría del desarrollo a escala humana: Buscando experiencias para la transformación social. Bogotá: Funlibre, 2008.2 Disponível em: http://www.redcreacion.org/documentos/congreso10/RElizalde.html

GALEANO, E. Las palabras andantes. Montevideo: Siglo XXI, 1994.

GUATTARI, F. As três ecologias; tradução Maria Cristina F. Bittencourt. Campinas, SP: Papirus, 1990.

HINTZE, H.C. Ecoturismo na cultura de consumo: possibilidade de Educação Ambiental ou espetáculo? Revista Brasileira de Ecoturismo, São Paulo, v.2, n.1, 2009, p. 57-100.

MARCELLINO, N.C. Estudos do lazer: uma introdução. Campinas-SP: Autores Associados, 1996.

PINHEIRO, B.R.A; SOARES, A.S.; AZEVEDO, F.F. A relação homemnatureza e a práxis do turismo: um (re)encontro para a preservação. Revista Brasileira de Ecoturismo, São Paulo, v.3, n.2, 2010, p.331-340. 
REDCLIFT, M. Os novos discursos da sustentabilidade. In: FERNANDES, M.; GUERRA, L. (Orgs.). Contra-discurso do desenvolvimento sustentável. Belém, Associação de Universidades Amazônicas, 2006, p. 51 76.

SACHS, I. Pensando sobre o Desenvolvimento na Era do Meio Ambiente. In: SACHS, Ignacy. Caminhos para o desenvolvimento sustentável. Rio de Janeiro: Garamond, 2002, p. 47-63.

SACHS, I. Desenvolvimento: includente, sustentável, sustentado. Rio de Janeiro: Garamond, 2004.

SERRANO, C. A educação pelas pedras: uma introdução. In: SERRANO, C. (org). A educação pelas pedras: ecoturismo e educação ambiental. São Paulo: Chronos, 2000, p. 07-24.

SERRANO, C. Uma introdução à discussão sobre Turismo, Cultura e Ambiente. In: SERRANO, C.; BRUHNS, H.T.(orgs). Viagens à natureza: turismo, cultura e ambiente. Campinas, SP: Papirus, 1997, p. 11-25.

WCED - World Commission on Environment and Development: Our Common Future. Oxford: Oxford University Press, 1987.

\section{Nota:}

1 As ideias apresentadas neste artigo integram a pesquisa "Lazer, sustentabilidade e meio ambiente na América Latina". Essa investigação contou com o apoio do CNPq (Edital Universal) e da Fapemig (Programa Pesquisador Mineiro - PPM-6), instituições às quais registramos agradecimentos.

Mirleide Chaar Bahia: Universidade Federal do Pará, Belém, PA, Brasil.

E-mail: cici.w@gmail.com.

Link para o currículo Lattes: http://lattes.cnpq.br/6052323981745384

Christianne Luce Gomes: Universidade Federal de Minas Gerais, Belo Horizonte, MG, Brasil.

E-mail: valeriaraujoufrn@gmail.com.

Link para o currículo Lattes: http://lattes.cnpq.br/3397229266029271

Rodrigo Elizalde: Universidade Federal de Minas Gerais, Belo Horizonte, MG, Brasil.

E-mail: drasoniatrigueiro@gmail.com.

Link para o currículo Lattes: http://lattes.cnpq.br/4817560075741050 
Leonardo Lincoln Leite de Lacerda: Universidade Federal de Minas Gerais, Belo Horizonte, MG, Brasil.

E-mail: drasoniatrigueiro@gmail.com.

Link para o currículo Lattes: http://lattes.cnpq.br/3048899576738254

Rodrigo Lage Pereira Silva: Universidade Federal de Minas Gerais, Belo Horizonte, MG, Brasil.

E-mail: drasoniatrigueiro@gmail.com.

Link para o currículo Lattes: http://lattes.cnpq.br/2826904637351686

Data de submissão: 02 de março de 2015

Data de recebimento de correções: 07 de agosto de 2015

Data do aceite: 07 de agosto de 2015

Avaliado anonimamente 